\title{
Linking water contents in mantle pyroxenes and $\mathrm{Fe}^{3+}$
}

\author{
I. B. RADU*1, H. SKOGBY ${ }^{1}$, G.H. HowARTH ${ }^{2}$
}

${ }^{1}$ Department of Geosciences, Swedish Museum of Natural History, Box 50007, SE-104 05, Stockholm, Sweden

(*correspondence: bogdana.radu@nrm.se)

${ }^{2}$ Department of Geological Sciences, 13 University Avenue, Universty of Cape Town, Rondebosch 7701, South Africa

The incorporation and preservation of hydrogen (water) in nominally anhydrous minerals is of great interest, particularly due to the effects of water on the physical properties of the mantle (e.g. enhances melting, increases electrical conductivity). Although ideally anhydrous, pyroxenes may contain several hundred ppm of water at high pressure and temperature conditions, and are comparatively the most water-rich nominally anhydrous mineral in the mantle. Nevertheless, hydrogen accommodation in the pyroxene structure is still poorly understood.

Previous studies have argued that water as hydroxyl $(\mathrm{OH})$ is preferentially incorporated on the $\mathrm{O} 2$ position, with charge compensation given either by cation vacancies in the M2 site, or charge-deficient substitution in the tetrahedral site. Previously, the total water content has been positively correlated with M2 vacancies accompanying Ca-Eskola [1] in clinopyroxene and $\mathrm{OH}$ absorbance bands at $3650-3540 \mathrm{~cm}^{-1}$ have been related to the amount of $\mathrm{Al}$ in the tetrahedral site [2]. The structural accommodation of $\mathrm{OH}$ is however challenging, as stoichiometric calculation of the $\mathrm{Fe}^{3+}$ content are not reliable and this error further propagates when calculating the amount of Ca-Eskola and $\mathrm{Al}^{\mathrm{IV}} / \mathrm{Al}^{\mathrm{VI}}$. Moreover, pristine mantle pyroxene, free of nano-inclusions of secondary minerals such as sheet silicates are scarce.

This study combines $\mathrm{Fe}^{3+}$ quantification via Mossbauer spectroscopy with $\mathrm{OH}$ determinations using Fourier Transform Infrared Spectroscopy, applied on pyroxenes from pristine mantle websterites and eclogites. The wide compositional variability along with the lack of contaminants ensure a more reliable dataset and allow the detailed study of the linkage between $\mathrm{Fe}^{3+}$ and water incorporation as hydroxyl at mantle conditions.

[1] Skogby et al. (2016) Eur. J. Mineral.28, 631-639.

[2] Koch-Müller et al. (2004) Am. Min. 89, 921-931 